\title{
O jornalismo e a matéria dos sonhos
}

\section{Andrea Limberto Leite}

\section{Resumo:}

Resenha do livro $O$ sonho da casa no campo: jornalismo e imaginário de leitores urbanos.

\section{Palavras Chave:}

Gislene Silva, jornalismo, imaginário.

\section{Abstract:}

Book review $O$ sonho da casa no campo: jornalismo e imaginário de leitores urbanos.

\section{Keywords:}

Gislene Silva, journalism, imaginary.

\section{SILVA, Gislene. $O$ sonho da casa no campo: jornalismo e imaginário de leitores urbanos. Florianópolis: Insular, 2009. 312pp.}

“(...) We are such stuff / As dreams are made on; and our little life / is rounded with a sleep”

(William Shakespeare) (1).

Podemos nos questionar sobre onde estaria hoje, no âmbito da cultura, o espaço para o desenvolvimento de mitos e para afirmação de posições sociais, já que temos vivido um aparente triunfo da racionalidade e do ser individual primando por sua autenticidade. Se a vitória desses parâmetros é indiscutível e seu efeito totalizante, então teremos que explicar a devoção particular de leitores da revista Globo Rural aos conteúdos nela publicados a partir da fruição das histórias contadas no formato de matérias jornalísticas.

Ao nomear matérias jornalísticas como histórias contadas falamos aqui em dois campos tomados constantemente em dicotomia, o fruir histórias, atividade mais próxima do que nos oferece a arte, mais especificamente a literatura e, do outro lado, a prática jornalística. Gislene Silva, em $O$ sonho da casa no campo: jornalismo e imaginário de leitores urbanos, obra derivada de sua tese de doutoramento, principalmente através dos conceitos articulados em torno da idéia de imaginário, leva-nos ao ponto de encontro em que a ficção e a capacidade de fabular tocam a construção de um sonho realista, que podemos chamar de um sonho em vigília, que é o de possuir uma casa no campo. Poderíamos dizer que reportagens trabalham sobre sonhos de caráter realista, se consideramos que no limite elas são construções de um imaginário e, no caso, lidam com objetos concretos.

Ter uma casa no campo se mostrou uma idéia recorrente nas falas dos assinantes de Globo Rural entrevistados pela autora. A composição dessa casa ideal é uma experiência muito particular de cada um 
deles e, no entanto, ganha materialidade e lastro social nas páginas da revista. Textos e fotografias identificam a vida no campo e dessa forma alimentam a imaginação dos leitores ao mesmo tempo em que dão vazão ao que estes constroem, a ponto de não sabermos mais se essa casa está localizada numa dimensão ou outra, na elaboração particular de um leitor ou unicamente nas páginas da revista. A pesquisa vive esse dilema.

Um pesquisador dedicado à Globo Rural poderia questionar quanto à atenção dada ao caráter informativo da revista, os dados técnicos que apresenta, se essa não seria sua faceta mais importante e uma entrada mais apropriada para uma jornalista na investigação sobre um periódico. O trabalho de Gislene Silva nos apresenta uma perspectiva em que essa valoração não se aplica, não faz sentido. As dimensões informativa e factual, mítica e fabular se fundem.

No ponto de encontro a que somos levados combinam-se ainda temporalidades diversas (presente, passado e futuro com fronteiras borradas), a dicotomia entre natureza e civilização, entre sonho e realidade, e também as dimensões do individual e do social. Esses são os grandes temas sobre os quais a pesquisa se detém para investigar o caráter das imagens da casa no campo desenhadas pelos leitores de Globo Rural. Mais do que uma temática pontual e setorizada, como seria de se pensar de um estudo tratando um periódico específico, destinado a um tema específico, nos deparamos com questionamentos sobre a prática jornalística e seu contato com a ficção, muitas vezes tratado de maneira ingrata.

O trabalho tem como principal material de investigação formulários respondidos e uma posterior tomada de depoimentos de uma parcela dos assinantes da revista em questão com perfil específico: não possuem propriedade no campo, não fazem do campo sua principal fonte de renda e ainda assim são leitores assíduos da publicação. É na investida para entender esse fenômeno que a pesquisadora se lança o desafio de observar o que sustenta o identificar-se com o material publicado.

Vale ressaltar a acentuada proximidade da autora com seu objeto de pesquisa, a partir da experiência de ter trabalhado por 11 anos na revista que se propõe a analisar, de forma que pode então cercar seu objeto com um olhar sobre o pacto com o leitor suposto na revista - essa é a perspectiva de quem produz - e ao mesmo tempo com a deposição de conteúdos feita pelos leitores sobre aqueles publicados - a perspectiva de quem lê (acesso ao leitor real ou a um leitor real). A primeira das perspectivas não aparece de forma explícita no trabalho, mas como não poderíamos deixar de pensar, está presente no falar sobre o objeto simplesmente por fazer parte da experiência complexa da autora com aquilo que observa.

Estudar o pacto com o leitor poderia se resumir na identificação de um leitor imaginário estruturado nas próprias edições. Sua formação é dialógica por princípio, pois ainda que não se converse com potenciais leitores de um periódico a escrita de suas matérias prescindem estruturalmente da pressuposição desse leitor. É interessante observar, no caso do trabalho de Gislene Silva o contraste, encontros e desencontros entre o leitor ideal (para quem conhece a publicação) e o que imaginam os leitores a que a autora dá voz.

$\mathrm{Na}$ estruturação final do texto do trabalho, evidenciando as duas frentes da pesquisa, investigação teórica e contato com leitores, o que se apresenta tem também assim dois estilos de escrita totalmente diferentes, um texto teórico intercalado com depoimentos de leitores, trechos editados das entrevistas feitas. O texto teórico recorta conceitos enquanto os depoimentos dos leitores são recortados tematicamente. De forma justaposta, um rico material bruto de entrevistas foi reunido desafiando a autora a fazer sua interpretação.

$\mathrm{Na}$ estrutura geral em capítulos, um corte criativo foi feito no sentido de captar o lugar de fala das pessoas entrevistadas, fincando um tripé no passado, outro no presente e um terceiro ainda no futuro. Tal é a divisão do trabalho em três capítulos, baseada em verso de Manoel de Barros: o olho vê (Capítulo I), a 
lembrança revê (Capítulo II), e a imaginação transvê (Capítulo III).

Essa divisão não é casual e estabelece os três tempos que integram a narrativa, observados nas entrevistas com os leitores da publicação: o passado vivido no campo, o presente de perda na cidade e o sonho com um futuro de retorno e um momento de restituição com a vida no campo ou o sonho da volta ao rural. Essa é uma divisão meramente didática para um fenômeno que se revela transcendente, instaurado num momento em que esses tempos se unem, escapando a uma ordem espaço-temporal linear.

O que está disponível na sucessão linear dos eventos, quanto ao tempo, é a ordem das atividades ligadas ao cotidiano, e quanto ao espaço, lá está a cidade. E é desse lugar que fala o leitor urbano. Nesse sentido, ele é um ser desprovido de algo, desprovido do campo e só pode sonhar aquele que está privado do objeto de seu amor. Tal objeto tem o poder de condensar em si memórias idílicas do passado, ausência sentida no presente e promessa de ressarcimento futuro. O tempo pára nesse ponto captando sinais desse objeto que tem contornos mutantes, toma forma nos discursos que falam de si e podem se espalhar em manchas gráficas e fotos emolduradas.

Os estilhaços perdidos de tal objeto são pistas de um imaginário que se completa nas paisagens dadas a ver. O tempo histórico, seqüencial, caro ao jornalismo, fica estagnado num momento de contemplação. E então, o que se vive em êxtase - mais do que a tentativa de contato com uma realidade - é um sonho ou ilusão dos fatos.

Findo esse trajeto retorna-se ao que seria o presente, com hora e lugares determinados, mas agora com olhar de estrangeiro. E esse olhar só tem aquele que vive nas entranhas da cidade, habituado com ela, que sente o que falta nela para lhe satisfazer.

Sonhar, nessa situação, é fugir do tempo presente, tempo histórico que marca a sucessão dos eventos a que nos prendemos. É ganhar um respiro num tempo que se mostra cíclico, em que momentos sempre retornam para serem reapreciados. Também o que é linear e o que é cíclico estão presentes de forma concomitante nos textos da revista e nos depoimentos de seus leitores.

O fato do objeto de pesquisa tratar-se de jornalismo em revista nos dá maior margem para investigar sobre a capacidade de fabulação na construção das matérias, que estaria, na outra ponta onde se encontra o leitor, dando vazão aos sentimentos de saudades do campo. O trabalho de texto e imagem, nesse caso, não é tão concentrado na apresentação factual como seria no jornalismo com compromisso diário. A pequena diferença na delonga para compor a matéria jornalística permite imbuir o material mais de um caráter de fruição. Esse dado, embora não faça parte do estudo de Gislene Silva um estudo comparativo, é ensejado pelo tipo de material com que se trabalha.

A surpresa da pesquisa, que ficará guardada aos que forem ao texto original, está na imagética do sonho com a casa no campo. A autora deixa entrever nos depoimentos que coletou o desenho imaginário de como seria esse lugar paradisíaco. No contar de cada um sobre seu sonho vemos um ponto sendo aumentado, como se um quadro se fizesse a muitas mãos, como parte de um legado social.

Para chegar a essa construção a autora tenta avaliar como seria o processo de elaboração de um conteúdo de caráter mais mítico, percorre a seara da deposição da memória, do material onírico (do sonhar e do sonhar acordado), do material imaginário, imagético e da imaginação. São plurais as entradas a esse conteúdo sincrético identificado nos leitores, desafio de análise da pesquisa e que se adere ao conteúdo apresentado na revista.

A autora justifica sua preferência por esse caminho mais tortuoso do que seria a análise das edições da 
revista: seu envolvimento durante anos na produção do periódico poderia marcar demais os resultados de análise. E assim, traça-se um caminho de investigação que é mais árduo, mas também mais rico no sentido de permitir que o objeto de pesquisa seja formado a partir de perspectivas diversas, um percurso surpreendente que não se anuncia simplesmente a partir da proposta inicial de trabalho.

As perspectivas teóricas se unem no trabalho construindo uma rede de maneira a recobrir um vão central, que diz respeito ao lugar destinado à realidade dos fatos. Num ambiente em que as imagens oscilam entre paradoxos de uma natureza que pode ser mãe e ameaçar, de uma cidade que pode ser luz ou desgraça haveria a necessidade de buscar decidir o verdadeiro, o autêntico? $O$ apego ao autêntico se associa à busca disso que está na raiz (não midiatizado, socializado) e que pode de alguma forma representar um acesso a um retorno às origens.

Como alerta a autora, não há interesse em distinguir a atividade literária da jornalística, dizendo que a primeira teria maior valor e que a segunda, no caso do objeto de pesquisa, estaria tentando equiparar-se. Ao mesmo tempo não se pode excluir da leitura de um texto jornalístico o caráter de fruição estética e narrativa. Em dado momento fala-se na condição de segredo que está no sonho curtido pessoalmente por cada leitor. Talvez possamos pensar que sem saber exatamente o conteúdo daquilo que está selado e que a revista veicula em suas páginas, entrega-se periodicamente os elementos que compõem os enigmas dos sonhos e que desatam, nos conceitos retomados pela autora, "processos mitopoéticos vivos".

\section{Bibliografia:}

SILVA, Gislene. O sonho da casa no campo: jornalismo e imaginário de leitores urbanos. Florianópolis: Insular, 2009.

\section{Notas:}

(1) "Somos feitos da mesma matéria dos sonhos e nossa curta existência é rodeada de sono" (William Shakespeare, The Tempest, Act 4, scene 1, pp.148-158).

\section{Mini Currículo :}

Doutoranda do Programa de Pós-Graduação em Ciências da Comunicação da Escola de Comunicações e Artes da USP, pesquisando sob orientação da Profa. Dra. Mayra Rodrigues Gomes as figuras de linguagem censuradas nas peças teatrais do Arquivo Miroel Silveira. Mestre em comunicação e bacharel em jornalismo pela mesma Escola. 